\title{
3. LAS LIBERTADES PÚBLICAS COMO GRUPO DE DERECHOS CON CARACTERISTICAS PROPIAS NO SUSCEPTIBLE DE SER CONFUNDIDO CON LOS RESTANTES DERECHOS CONSTITUCIONALES
}

REMEDIO SANCHEZ FÉRRIZ

Universidad de Valencia 


\section{SUMARIO}

I.-LIBERTADES PÜBliCAS. Il.-POSICIONES DE LA DOCTRINA FRANCESA ACTUAL. III.-DETERMINACIÓN DE LAS LIBERTADES PÚBLICAS. 1. LaS libertades públicas son derechos cuyo reconocimiento no resulta grato al poder. 2. Las libertades públicas categoria intermedia entre los derechos individuales y los politicos. 3. Las libertades públicas son las que mayor carga de politización contienen. 4. Las libertades públicas como derechos limitados. IV.-El CATAlogo de las libertades públicas. 1. Homogeneidad del grupo pese a su historicidad. 2. Enumeración de las libertades públicas. 
Revista de Derecho Político, núm. 30, 1989, pp. 55-73

\title{
3. LAS LIBERTADES PÚBLICAS COMO GRUPO DE DERECHOS CON CARACTERISTICAS PROPIAS NO SUSCEPTIBLE DE SER CONFUNDIDO CON LOS RESTANTES DERECHOS CONSTITUCIONALES
}

\author{
POR \\ REMEDIO SÁNCHEZ FÉRRIZ \\ Universidad de Valencia
}

I. LIBERTADES PÚBLICAS

Una simple lectura de la bibliografía relativa a los Derechos y Libertades nos advierte de una constante que se observa con claridad en el uso que la doctrina y el legislador hacen de dichos términos: el uso indiscriminado o casi indiscriminado de los términos derechos y libertades. Pese a ello, creo que vale la pena reflexionar sobre la expresión "Libertades Públicas», que no siempre halla reflejo en la, apenas utilizada (al menos, en la misma acepción de aquélla), de «derechos públicos». Varias corrientes doctrinales se implican aquí y de modo principal la escuela francesa, la tradicional inclusión de la disciplina en los planes de estudio franceses y su recepción entre nosotros.

Se ha dicho que el propio TC nos ha advertido sobre la acepción constitucional (española) que tiene la expresión «libertades públicas» que, al estar incluidas en la sección $1 .^{\circ}$ del Capitulo II del Título I de la Constitución, cuentan con una protección reforzada a la que no pueden acogerse los derechos no comprendidos en tal sección (Sent. 98/85, t.j.4). Ello es cierto; sólo que esta afirmación, en nuestro caso, carece de valor clarificador alguno porque lo que se predica de las libertades públicas es también predicable de los derechos «fundamentales" contenidos en la misma sección (arts. 15 a 29): ambas categorías son similares en cuanto a su ubi- 
cación, calificación y protección jurídica '. Y en cambio, lo que nos estamos preguntando es si el uso de las dos expresiones es indiferente porque ambas acabarían agrupando los mismos derechos o hay alguno de ellos en que la distinción es aconsejable por traducir una realidad jurídica distinta.

El mismo planteamiento de la cuestión, tal como lo hemos formulado, parte de un hecho indiscutible: hay un amplio margen de coincidencia, entre ambas categorias; ambas expresiones son igualmente ajustadas al objeto de designar buena parte de los derechos del hombre, pero ¿lo son también y de igual modo para designar la globalidad de estos derechos? Pese a la dificultad que entraña el empeño de trazar una línea divisoria entre lo que les es común y lo que les es propio, pese a la confusión con que se utilizan y pese a la indispensable función de complementariedad que una y otra expresión se prestan, sl creemos posible su distinción aunque con el carácter residual ya apuntado.

Para tratar de hallar el origen de la expresión «libertades públicas» es interesante recordar con COLLIARD ${ }^{2}$ el uso inicial de la expresión en Francia (que se vincula al derecho positivo) ${ }^{3}$.

Los textos revolucionarios de fines del siglo XVIII emplean con frecuencia la palabra libertad pero sin añadirle el adjetivo «pública». Apenas si podría citarse el articulo 9 de la Constitución de 1973, según el cual «/a loi doit protéger la llberté publlque et individuelle contre l'oppression de ceux qui gouvernent». Pero debe hacerse notar que el término es utilizado en singular y asi será empleado también en la exposición de motivos de la Carta constitucional de 1814. En plural, tal como hoy suele emplearse, pero con una acepción diferente, fue utilizado con frecuencia por algunos autores tradicionalistas, especialmente por Chateaubriand, durante la Restauración. Luego su uso se fue generalizando entre los publicistas al estudiar los «Drois publiques des français" proclamados en los artículos 1 al 12 de la Constitución de 1814. Se ha señalado que no deja de ser una paradaja que la primera vez que aparece el término Ilbertés publiques en un texto constitucional sea precisamente en el artículo 25 de la Constitución del II Imperio de 1852, en donde se hace del Senado el "gardien du pacte fondamental et des libertés publiques».

A partir de aqui, el término se inserta en la tradición política republicana de Francia. Ciertamente, los textos constitucionales de la III República en su laconismo y empirismo no la utilizan y si las leyes procla-

\footnotetext{
Algo semejante ocurre con la famosa decisión del Consejo Constitucional Francés de 16 de julio de 1971 (sobre la libertad de asociación) en cuya virtud asimila libertades públicas y derechos humanos confiriéndoles el mismo valor constitucional tras el reconocimiento del valor jurídico del Preámbulo de la Constitución. Para más detalles sobre esta decisión, puede verse por todos, G. PECEs BARBA: Libertad, poder y socialismo. Madrid, Civitas, 1978, págs. 16 y ss.

2 Cl. A. Colliard: Libertes publiques. Paris, Dalloz, págs. 14 y ss.

3 Conviene tener presente esta idea por lo que después se dirá.
} 
maban y definian las libertades se trataba en cada ocasión de cada libertad particular y no de un conjunto de ellas. Fueron los autores quienes operaron la síntesis; así, el decano DUGUIT titula el Tomo II de su Tratado de Derecho Constitucional (1911) Les Libertés publiques y ésta es la expresión que utiliza también Berthelemy. Es, con todo, durante la IV República cuando la expresión alcanza a ser una auténtica categoría jurídica constitucional, status que mantiene bajo la V República. Ello se logra, dice COLLIARD, en dos ámbitos:

En primer lugar, el concepto se delimita con ocasión del establecimiento de competencias respecto de los territorios de ultramar: el derecho de 3-diciembre-56 reservaba al Estado «las relaciones exteriores, la defensa, la garantía de las libertades públicas...» por cuanto constituyen intereses generales de la República. Más decisiva es para nuestro objeto la interpretación dada por el Consejo de Estado (13-VIII-47) al artículo 72 de la Constitución de 1946. Según este precepto, en los territorios de ultramar el poder legislativo corresponde al Parlamento en lo que se refiere a la legislación criminal, al régimen de las llbertades públlcas... El Consejo de Estado, al interpretar este artículo establecla con claridad (que a mi juicio, después, ha quedado desdibujada o no se ha tenido en cuenta) un catálogo de libertades públicas:

«El término libertades públicas comprende, con independencia de la libertad individual, las grandes libertades que «n'etant pas limités a l'individu seul, se manifestent au dehors et comportent l'action de co-participants ou l'appel au public»; en consecuencia, se incluyen obviamente en esta categoría de las libertades públicas la libertad de reunlón, la IIbertad de asociación, y con ella la llbertad sindical, la llbertad de prensa y, de modo general, la difuslón del pensamlento, la libertad de conciencla y de cultos, la libertad de enseñanza" 4 .

En segundo lugar, también durante la IV República, las libertades públicas van a verse reservadas al Poder Legislativo de modo que quedan excluidas no sólo de la posibilidad de verse afectadas por los poderes descentralizados en los territorios de ultramar, sino también de las competencias del Ejecutivo, ya sean reglamentarias o de legislación delegada.

En la vigente Constitución francesa de 1958 se mantiene la reserva legal (aunque restringiendo su contenido a sólo las garantías de las libertades públicas) pero poco se aporta a la cuestión de su determinación conceptual que ahora nos ocupa. Colliard, insistiendo en la falta de precisión

4 Cl. A. Colliard, op. cit., pág. 16. 
de que siempre ha adolecido la expresión, acaba proponiendo una definición que podría girar en torno a tres factores:

1. Las relaciones entre el individuo y el poder público.

2. El carácter colectivo de estas libertades, y

3. su carácter negativo frente a las prestaciones positivas.

Sin embargo, un análisis detallado de los mismos le lleva a desecharlos, al menos como factores decisivos, para acabar centrando su atención, aun sin reconocerlo, en las facultades prácticamente omnímodas que los poderes públicos poseen (sobre las libertades públicas) como referencia última para comprender qué son (lógicamente, en cada momento) y cómo se delimitan las libertades públicas. Así, define el autor las libertades públicas como «situaciones juridicas legales y reglamentarias en las que el individuo halla reconocido el derecho de actuar (agir) sin sobrepasar el marco de los límites fijados por el derecho positivo vigente y eventualmente determinados, bajo el control jurisdiccional, por la autoridad de policía encargada del mantenimiento del orden público. Este derecho es protegido por una acción, esencialmente por el ejercicio de control de legalidad» 5 .

\section{POSICIONES DE LA DOCTRINA FRANCESA ACTUAL}

Pues bien, este planteamiento positivista (a partir del cual parece olvidarse la distinción, si la hay, entre las libertades públicas y las que no lo son) es el que con unos $u$ otros matices se halla en la doctrina francesa (la que de modo más difuso ha estudiado y explicado la materia) y en la española que suele seguir los pasos de aquélla. Ciertamente, la doctrina francesa contempóranea no aporta tampoco fundamentación de peso para precisar conceptualmente las libertades públicas y, sin embargo, sigue manteniendo viva la cuestión de su no confusión con los derechos en general, que bien pudo obviar aceptando el uso indiscriminado de ambos términos (libertades y derechos como, en definitiva se suele hacer). Asi, PELLOUX afirma abiertamente que son una misma cosa, y que no tiene

- A. COLLIARD, op. cit., pág. 25. 
sentido proceder a su distinción ${ }^{6}$. Pero esta actitud no es mayoritaria como acabamos de decir; al contrario, los autores tratadistas franceses (dice PECES BARBA ${ }^{7}$, afirmando la corrección de esta terminologia) suelen llamar libertades públicas a los derechos fundamentales que forman parte del Derecho positivo. La afirmación, sin embargo, creemos que exige alguna precisión ${ }^{8}$ :

Ciertamente, tal es el punto de partida de muchos tratadistas franceses pero vale la pena recordar algunos de sus matices respectivos. Es el punto de partida, por ejemplo, de Rivero y de Colliard bien que éste la mantenga desde un enfoque estrictamente positivista y aquél, en cambio, sostenga su compatibilidad con una fundamentación iusnaturalista; entiende RIVERO ${ }^{9}$ que las nociones de derechos del hombre y de libertades públicas son vecinas $y$, sin embargo, bien diversas porque ni se sitúan en el mismo plano ni tienen el mismo contenido porque sólo son libertades públicas los derechos que han alcanzado, con todas sus consecuencias jurídicas, la positivación; sólo que tampoco lo son todos los derechos positivizados pues no son libertades públicas los derechos sociales.

Semejante es la posición de SOULIER ${ }^{10}$ cuando recuerda que la noción de derechos del hombre es hoy más amplia que la de libertades públicas, todas las libertades públicas son Derechos del hombre pero no todos los derechos del hombre son libertades públicas porque aquéllos se han extendido a los derechos económicos y sociales qùe no constituyen propiamente Libertades Públicas ni tienen, su mismo régimen jurídico ya que estos derechos contemporáneos no quedan asegurados por la sola intervención del Derecho mientras que las libertades públicas quedan esencialmente garantizadas por la técnica jurídica.

- R. Pelloux: Introduction à l'étude des droits de l'home et des libertés foridamentales en Europe, en la ob. col, "Essais sur les droits de l'homme en Europe» (Première série), Ed. de l'Institut Universitarire d'Etudes Europeennes, Turis, 1959, pág. 177, cit. por L. PÉREz LuNo: Derechos Humanos, Estado de Derecho y Constitucion. Madrid, Tecnos, 1984. Tal uso indistinto puede verse en la otra, también de PELloux: Le citoyen devant l'État. Paris, PUF, 1963. Tampoco procede a analizar distinción alguna, J. MORANGE: Libertes publiques. PUF, 1984, aunque parece darla por supuesta (en el sentido con que generalmente lo entienden los franceses) al decir que aquellos derechos que los nacionales, en cada pais, tienen reconocidos por el derecho positivo constituyen para ellos «sus libertades públicas" (pág. 14).

7 G. Peces Barba: Derechos fundamentales. Latina Universitaria, pág. 101.

s Según J. Roche: Libertés publiques. Paris, Dalloz, 1981, (pág. 5) la noción de libertades públicas ha adquirido carta de naturaleza en la doctrina, en la Jurisprudencia y en el Derecho positivo, y, sin embargo, es una noción incierta y necesitada de mayor precisión puesto que no hay una definición que haya sido acogida con unanimidad por la doctrina ni existe definición legal alguna ni, hasta 1977, habia pronunciamiento jurisprudencial alguno; en este año, en decisión de 18 de junio de 1977, el Tribunal de Caen diría que «las libertades públicas son los derechos reconocidos y garantizados por las autoridades públicas». Insiste también sobre la confusión e indeterminación de la expresión E. Pérez LuÑo: Derechos Humanos, ya cit., págs. 35 y ss. 24-25.

J. Rivero: Les libertés publiques I. Les Droits de I'Homme. Paris, PUF., 1981, páginas

10 G. Soulier: Nos droits face à l'Etat. Editions du Seuil, 1981, págs. 27-28. 
En cambio, BURDEAU ${ }^{11}$ cree que, aun cuando establezcamos distinciones a nivel expositivo y con carácter pedagógico, la solidaridad de los derechos obliga a no establecer distinciones prácticas e, incluso, a considerar los derechos sociales como libertades públicas. Aunque con argumentación bien distinta y sin reconocerlo expresamente, llega a la misma conclusión MADIOT ${ }^{12}$ : si las libertades públicas son derechos pero si no todos los derechos son libertades públicas, y además, no hay un criterio concreto para distinguir en el seno de los derechos cuáles merecen ser calificados como libertades públicas, habrá de reconocerse que el problema de la definición deviene prácticamente insoluble; por ello, el autor prefiere la denominación de los derechos del hombre a pesar del título oficial de la asignatura que en Francia los estudia, llegando a decir que no tiene sentido el de las libertades públicas: « ¿en qué sentido es pública una libertad? No hay libertades privadas, toda libertad supone una intervención del Estado... Existe una unidad real y profunda de los derechos del hombre y las libertades públicas que no hacen, de hecho, sino traducir el conjunto de posibilidades de desarrollo del individuo" ${ }^{13}$.

También RIVERO se plantea el problema aunque llegando, como ya se ha visto, a la conclusión de que todos los derechos positivados (salvo los sociales) son libertades públicas, lo que evidentemente, no resuelve el problema aquí planteado. Veamos su línea de argumentación que, como un ejemplo más, prueba la dificultad de establecer delimitaciones en este campo y la consiguiente facilidad con que puede caerse en la contradicción: el autor ${ }^{14}$ recuerda cómo el término «públicas» denota, en principio, intervención del poder (pero interesa ver su significado respecto de las libertades) y cómo de las libertades públicas se ha dicho que son las que afectan a las relaciones entre los órganos del Estado y los ciudadanos, a diferencia de las privadas que afectarian a las relaciones entre particulares; lo que, para Rivero, no es aceptable porque no existen las libertades privadas, todas son públicas en la medida en que sólo son tales cuando el Estado las consagra y pasan a formar parte del ordenamiento jurídico positivo pues lo contrario no tendría sentido (p. ej., la libertad sindical sería pública cuando se desarrollara en las empresas públicas y privada cuando se ejerciera respecto de las privadas); lo que le lleva a definir las libertades públicas como «poderes de autodeterminación consagrados por el derecho positivo".

$Y$, sin embargo, el autor sigue distinguiendo las libertades de los derechos (son nociones vecinas, dirá, pero bien diversas por que ni se sitúan en el mismo plano ni tienen el mismo contenido) ${ }^{15}$ : en cuanto al

G. Bundeau: Les libertés publiques. Paris, LGDJ, 1972, pág. 97-98.

Y. MADIOT: Droits de l'homme et libertés publiques. Paris, Masson, 1976, pág. 16.

lbidem, pág. 14.

J. Rivero, op. cit., pág. 23.

lbidem, pág. 25. 
plano en que se sitúan, los derechos del hombre hallan su fundamento en el derecho natural y las libertades públicas se insertan en el derecho estatal ${ }^{16} y$, por lo que respecta a su diverso contenido, entiende el autor que las libertades públicas (LP) son poderes de elección que históricamente coincidian con los derechos a diferencia de los derechos que suponen exigencias respecto de terceros como lo son, hoy, los derechos de prestación ${ }^{17}$.

En definitiva, quienes niegan la distinción lo hacen por falta de argumentos suficientes en quienes la afirman y éstos centran el debate en torno a la exclusión de la última «hornada» de derechos dado que éstos no han alcanzado aún el nivel de positivación y defensa jurídica de las libertades o derechos precedentes. Pero, obsérvese que ello se afirma desde la perspectiva contempóranea. ¿Quiere decirse que en etapas anteriores, precisamente cuando se inicia el uso de la doble denominación, ya hay derechos que son libertades porque su régimen jurídico se halla perfilado y cuentan con suficiente garantía jurisdiccional y otros que no lo son pero que irán incorporándose sucesivamente?

Creemos que no; de ser asi, sólo recientemente pudo hablarse de libertades públicas en el sentido global (del conjunto de derechos de la primera y segunda generación según las teorías francesas que se han expuesto) y habría tenido que hablarse sólo de alguna libertad pública en concreto; asi, por seguir con el ejemplo francés, libertad pública tan evidente como es la de asociación sólo habría alcanzado en Francia su sentido pleno de tal con la sentencia de 17 de julio de 1971, por la que el Consejo Constitucional ha reconocido a las disposiciones de las principales leyes de desarrollo de las libertades valor constitucional y por tanto, protección plena en cuanto a la aplicación a las mismas del régimen jurídico propio

16 A mi juicio el argumento es contradictorio o, por lo menos no es decisivo, pues es discutible que precisamente los derechos prestacionales, aquellos que los autores franceses y en concreto el que ahora comentamos no consideran libertades públicas, hallen su fundamento en el Derecho Natural y no en la concreta política asistencial del Estado. En todo caso, situar la diferencia entre un grupo u otro de derechos y libertades simplemente en el dato del reconocimiento jurídico no puede ser hoy determinante porque las Constituciones de la segunda postguerra contienen un amplio catálogo de derechos en el que también se reconocen los que el autor llama prestacionales o derechos del hombre que no son libertades públicas.

También este argumento es discutible hoy por la complejidad de los actuales sistemas de derechos en los que, incluso muchos de ellos, aisladamente considerados, reúnen en sl mismos características de más de uno de los grupos tradicionalmente considerados. En este sentido, como recuerda Soulien (op. cit., pág. 50), un gran número de derechos y libertades son en realidad "Derechos complejos" cuya misma naturaleza es contradictoria y suponen a la vez intervención y abstención del Estado; lo que cabe observar no sólo en buen número de derechos económicos y sociales sino también en algunas libertades de carácter político. 
del que en otra sede (aunque tomando como ejemplo el español vigente) nos ocupamos ${ }^{18}$.

\section{DETERMINACIÓN DE LAS LIBERTADES PÚBLICAS}

En nuestra modesta opinión, la expresión libertades públicas ${ }^{19}$ puede aplicarse a buena parte de los derechos de las dos primeras «generaciones" pero no a todos ellos. Más exactamente, las libertades públicas constituyen la mayor parte de los derechos de la segunda generación (pues no contaremos entre ellas los derechos propiamente políticos). Y ello es Iógico si recordamos los postulados del primer constitucionalismo liberal: si éste desea un Estado mínimo y rechaza todo tipo de colectividad intermediaria entre éste y el individuo, es evidente que no se reconocerán las libertades públicas que puedan implicar organización estable. «Por lo tanto, el verdadero instrumento de mediación de esta sociedad atomizada, individualista y abierta, sólo podía ser la opinión pública concurrencial y abierta cuya explosión es paralela al propio desencadenamiento del proceso revolucionario. Así pues, el marco institucional de origen en el que se integran las libertades públicas como instrumentos de configuración del Estado, parece perfilar lo que en el sentido de Habermas podríamos calificar como un proceso intercomunicativo abierto y concurrencial en estado puro; su plasmación más directa sería, pues, la de los artículos 10 y 11 de la Declaración: libertad de opinión y de pensamiento, y libre comunicación de

18 De estos problemas, y particularmente del régimen jurídico de las Libertades Públicas nos ocupamos en el libro Libertades Públicas (Tirant Lo Blanch de Valencia, 1989).

${ }_{10}$ La idea de su especificidad, aunque no suele ser desarrollada por la doctrina, se evidencia en muchas ocasiones. AsI, por ejemplo, L. MARTIN RETORTILLO: Derechos fundamentales y Constitución, ya cit., pág. 38, al referirse al artículo $31, i$ ) de la Ley 30/84 de 2 de agosto de (de medidas para la reforma de la función pública) en el que se consideran faltas muy graves «la obstaculización del ejercicio de las libertades públicas y derechos sindicales", escribe lo siguiente: "... sin entrar en el delicado tema de donde se ubican los «Derechos Sindicales" -incluso, de si en buena medida los "derechos sindicales" no encajarian dentro del concepto de «libertades públicas»_... «... Por su parte, y de forma más directa (aunque a mi juicio algo restringida por reducir las libertades públicas a los derechos políticos) dice A. Porras («Libertades Públicas y Revolución Francesa», Conferencia pronunciada en la Facultad de Derecho de Valencia, el 10 de mayo de 1989) que en el Derecho Constitucional contemporáneo suele ser tópica «la distinción dentro de toda parte dogmática de la Constitución de dos esferas perfectamente diferenciadas, la de los derechos fundamentales y la de las libertades públicas. Mientras los primeros constituyen el ámbito fundamental de garantia de la Privacy, de la esfera de autonomia individual de los sujetos, que no debe ser interferida por los poderes públicos, en cambio las libertades públicas serían la expresión del status activo de los ciudadanos, de acuerdo con la conceptuación de Jellinek; es decir, constituyen los instrumentos que permiten la incorporación activa de los ciudadanos en el proceso de formación la voluntad del Estado representativo". 
ideas y opiniones, incluyendo la libertad de imprenta. Como señalara el Título Primero de la Constitución de 1791 , se trata de un espacio de confluencia o identificación entre derechos naturales y civiles, a partir de los cuales los ciudadanos pueden concurrir en la formación de la Ley como expresión de la voluntad popular» ${ }^{20}$.

Con todo, lo que importa resaltar es la idea de libertades públicas que aun sin manifestarse de modo expreso subyace en el pensamiento revolucionario aun cuando fuera para rechazarlas o silenciarlas porque, como advierte PORRAS ${ }^{21}$ sigue manteniéndose en su esencia; esto es, «las libertades públicas concebidas como instrumentos de encauzamiento de la libertad creadora de la sociedad civil sobre los poderes públicos». Creemos, pues, que vale la pena intentar una conceptuación de las libertades públicas que permita reconocerlas en sus peculiaridades distintas de los restantes derechos humanos o constitucionales.

En tal sentido cabría decir, de entrada, que los derechos-libertades públicas serían las que derivan directamente de la libertad humana y de su lógica manifestación exterior; son derechos que se exteriorizan, que se ejercen con relación a los demás aunque no necesariamente en forma colectiva pero que, en todo caso, pueden lograr, y aspiran a ello, una repercusión externa a su propio titular (aun en el ámbito propiamente político). Lo que, en cambio, no ocurre con los derechos o libertades individuales ni con los sociales.

De ahí que podamos observar en ellas las siguientes peculiaridades o notas: $1 .^{a}$ Que hayan sido siempre libertades «molestas" (o de incómodo reconocimiento) para el poder; $2^{2}$ Que, siendo expresión de la natural sociabilidad de la persona, se hallen a medio camino entre los derechos o libertades individuales y los políticos; 3.. Que hayan sido, no obstante no ser políticos, los de más fácil politización, y 4." Que su reconocimiento se vea acompañado de cautelas o condicionamientos 0 , en su caso, de remisiones a la ley. Veamos cada una de ellas.

\section{Las libertades públicas son derechos cuyo reconocimiento no resulta grato al poder}

En efecto, las libertades públicas representan históricamente, y hasta cabría decir que aun ahora, los derechos menos gratos o más «molestos" al poder. De una parte, la expresión pudo hallar éxito en su uso

\footnotetext{
20 A. PORras, Conferencia, ya cit.

21 lbidem.
} 
porque representa perfectamente la idea básica con que saltan a los textos fundamentales: las libertades públicas son espacios de libertad que se oponen frente al poder público, frente al Estado, lo que permite distinguirlas de las libertades a ejercer en relación con particulares; con tal criterio es evidente, por ejemplo, que cualquiera de las facultades del propietario sobre la cosa, ejercitables frente a cualquier tercero, no se entendió como libertad pública y sí, en cambio, frente a las posibles intromisiones del poder público. Así, dice PÉREZ SERRANO ${ }^{22}$ que «fundamentalmente, las "libertades constitucionales" se demarcaban, antes que por criterios filosoficos, por razones históricas; el hecho de que la Monarquía absoluta hubiere desconocido o conculcado determinados derechos era lo que obligaba a reafirmarlos con toda solemnidad... De ahí que ocupen un lugar preferente las libertades relativas a la seguridad personal y las referentes a su participación en el manejo de la cosa pública...".

De otra parte, como dice RUIZ DEL CASTILLO ${ }^{23}$, «la libertad — su reconocimiento - ha sido arrancada y el esfuerzo humano tiende siempre a libertarse de las fuerzas representadas por el poder", aunque también advierte este autor de los errores a que podria conducir la aplicación de este criterio de contraposición individuo-Estado, derivado de la historia, en la consideración jurídica de los derechos que, precisamente, hallan su reconocimiento y garantía en el Estado.

Porque (y éste es otro aspecto importante y decisivo que permanece en la esencia de las libertades públicas desde sus primeras formulaciones hasta las más actuales), en todo caso, se trata de una misma realidad pero contemplada en momentos sucesivos: la libertad es arrancada al poder pero sólo cabe hablar en rigor de libertades públicas cuando ese poder cuenta con algún componente democrático. En la base de la Revolución francesa, y de los movimientos liberales en general, se halla el Tercer Estado. Desde la oposición a las dictaduras actuales se exigen las libertades públicas $y$, apenas éstas entran a formar parte del discurso político del poder es porque hay un real (o aparente) propósito de democratización. Por ello, es cierto, como dice Ruiz del Castillo, que se ejercen en el marco y con la protección del Estado pero, como también veremos, la experiencia demuestra que su convivencia nunca llega a ser totalmente pacífica.

\section{Las libertades públicas categoria intermedia entre los derechos individuales y los politicos}

Desde otro punto de vista, las libertades públicas son expresión inmediata de la sociabilidad humana y, sin llegar a constituir derechos po-

22 N. Pérez Serrano: Tratado de Derecho Politico. Madrid, Civitas, 1976, pág. 605.

${ }^{23}$ C. Ruiz del Castillo: Derecho Politico. Madrid, Inst. Ed. Reus, 1939, pág. 315. 
líticos, forman un grupo diferente de los derechos individuales o más vinculados a la personalidad aislada del hombre. En este sentido, algo parece innegable y es la mayor carga política del término libertades y la mayor carga filosófica, iusnaturalista, e individualista, del término derechos; a ello parece referirse FERNÁNDEZ GALIANO ${ }^{24}$ cuando advierte, aun en la expresión derechos fundamentales, un sentido algo restrictivo "al aludir de modo preferente a una perspectiva política».

Desde luego que la explicación histórica (a que se acaba de hacer referencia), literalmente aplicada, podría conducir, como Ruiz del Castillo ha advertido, a errores de técnica jurídica pero, con todo, creo que sí nos permite explicar en buena parte su doble uso y hasta los matices diferentes que cabría hallar en el tratamiento jurídico de lo que cabe denominar derechos o libertades y de lo que, indiscutiblemente, son derechos y no libertades públicas.

Éstos serían los más inherentes al ser humano, los indiscutibles y los difícilmente limitables (la vida, la integridad física y moral, la intimidad); en cambio, derechos-libertades públicas serian los que tienen, según se ha dicho, una transcendencia o manifestación que busca hallar efectos (incluso políticos) fuera del estricto ámbito personal de su titular. SÁNCHEZ AGESTA ${ }^{25}$ halla su especificidad en el hecho de que tiendan a rebasar «ese carácter limitado de derechos que agotan su virtualidad en la persona” llegando a transformarse en "poderes sociales" que girarian, fundamentalmente, en torno a la opinión pública.

Pero, con todo, tampoco cabe considerarlos, sin más, derechos políticos en el sentido de instrumentos o pautas de actuación ciudadana encaminados a conformar la voluntad del Estado (en la realidad, a proporcionar soportes de legitimidad a los poderes públicos). A diferencia de los derechos políticos, las libertades públicas no buscan la conformación de la voluntad del Estado, sino la expresión de la sociedad subyacente al Estado, la expresión de su vida propia que puede no ser plenamente coincidente con la de aquél.

\section{Las libertades públicas son las que mayor carga de polltzación contienen}

Los derechos-libertades públicas son, por lo mismo, los de más fácil politización tanto desde la perspectiva de sus titulares como de la de los poderes públicos, siempre reacios a su reconocimiento.

24 A. Fernández Galiano: Derecho natural. Madrid, Ceura, 1987, pág. 262.

25 L. SAnchez Agesta: Principios de Teorla Politica. Madrid, Editora Nacional, 1972. 
Pues, en lo que respecta a los titulares, aun en los momentos históricos en que la reivindicación de las libertades públicas parecía reducirse a los propósitos y actividades más inofensivas (por ejemplo la asociación con fines culturales y hasta benéficos), siempre acaban siendo utilizadas con fines políticos (un ejemplo actual sería el de la libertad de huelga, inicialmente reivindicada a los solos fines profesionales, pero susceptible de ser utilizado en su caso, con objetivos políticos).

Quizá por ello, y sin desmentir la necesaria complementariedad de los términos derechos y libertades ${ }^{26}$, es posible observar en su uso una mayor facilidad para recurrir al término libertades cuando, aun tratándose de lo que pudiera ser denominado de un modo $u$ otro, quiere afirmarse su defensa, su potenciación frente al poder o, simplemente, frente a cualquier otro riesgo de minusvalorización. Cuando, en definitiva, se defiende la capacidad de actuación del titular; porque las libertades públicas sólo se ejercitan mediando una manifestación positiva de la voluntad de su titular; sólo a partir de ella cabrá hablar de, y experimentar la violación y consiguiente defensa jurídica de las mismas: no son derechos pasivos sino activos.

No así cuando utilizamos el término derecho: aun tratándose del mismo supuesto utilizaremos "derecho" para expresar su (relativa) plenitud, su accionabilidad o el convencimiento de su realidad para cuya conculcación y defensa no se requiere una previa y positiva manifestación de la voluntad del sujeto ${ }^{27}$.

Desde la perspectiva del poder también son derechos de fácil politización lo que explica que en todos ellos se cumpla el típico proceso histórico en el que han ido pasando de ser delitos a consistuir hechos tácitamente consentidos para, finalmente, ser admitidos como derechos. Ello explica también que, así como los derechos humanos, los de carácter individual, suelen ser reconocidos aun en los regímenes autoritarios (un ejemplo sería el régimen de Franco o el reconocimiento de los derechos tal como los contenía la Constitución de 1876) no sucede así con las libertades públicas que sólo se hallan plenamente reconocidas en los regímenes democráticos (los dos ejemplos anteriores son muy claros, bien que en el largo período de la Restauración hubiera también lugar para una progresiva democratización del régimen que permitiera, por la vía legal,

28 Véase mi libro Libertades Públicas, ya cit.

${ }^{27}$ F. GARCIA DE ENTERRIA ha distinguido, en efecto, entre derechos activos y reaccionales (vid. "Sobre los Derechos Públicos Subjetivos», en Civitas, núm. 6, 1975, pág. 427 y ss.). Con todo, y volviendo a la consideración hecha más arriba no cabe su confusión con los derechos politicos, aunque cabe hallar manifestaciones en contrario. (Así, J. A. GonzAlez Casanova (vid. nota siguiente) o J. M. Romero Moreno: Proceso y Derechos Fundamentales en la España del siglo XIX. Madrid, CEC, 1983, pág. 17). Lo que si hay a mi juicio es una relación entre ambos tipos en la que las libertades públicas constituyen el presupuesto de un ejercicio libre y consciente de los derechos políticos o de la conformación de la voluntad popular sin la que, en propiedad, no cabría hablar de democracia gobernante. En este sentido, por todos, cfr., W. J. MACKENZIE: Elecciones libres. Madrid, Tecnos, 1968, pág. 185. 
la introducción progresiva de las libertades que, sólo formalmente se hallaban recogidas, y no todas, en esta Constitución que recurria a la técnica de la desconstitucionalización mediante la remisión a la ley).

Tal politización (aquí doblemente aludida) deriva de la propia razón de ser de estas libertades. A mi juicio, es nota peculiar que dificulta su delimitación ${ }^{28}$ pero, sin duda, concurre en éstas con un carácter que las distingue de grupos vecinos, ya que esta politización de las libertades públicas puede escapar en ocasiones al control de los propios poderes públicos; lo que en cambio, no ocurre con los derechos politicos que, sobre estar perfectamente reglamentados, hasta el punto de escapar en buena medida al ámbito de la libertad ${ }^{29}$, se acompañan de técnicas a las que su ejercicio se somete (el caso del voto, sus estrictas condiciones y técnicas de emisión, sería quizá el ejemplo más relevante y palpable de lo que queremos expresar).

Ello explica las reticencias que se observan históricamente en su reconocimiento, como también, el que constituyan un grupo situado a medio camino entre los derechos o libertades individuales y los políticos (no susceptibles en todo caso de ser confundidos). Así también se explica el que los propios régimenes democráticos recurran a la suspensión de las libertades públicas cuando circunstancias extraordinarias lo aconsejan en defensa del propio orden democrático y constitucional ${ }^{30}$. Pero también se entiende con lo dicho que sean las libertades aquí estudiadas las que de manera especial permiten calificar un régimen de democrático, pues sólo en éste se manifiestan como se ha dicho ya, en sus múltiples posibilidades.

Sin perjuicio de su no coincidencia en la delimitación y conceptuación de las libertades públicas la doctrina sí coincide en esta afirmación básica de las libertades públicas como parámetro de la democraticidad de un régimen; en este sentido, GONZÁLEZ CASANOVA ${ }^{31}$, resaltando su im-

29 Con todo, la linea de demarcación no es estricta ni inamovible y las manifestaciones doctrinales revelan su naturaleza compleja. Así, J. A. GonzAlez CASANova (Teoria del Estado y Derecho Constitucional, Barcelona, Vicens Vives, 1987, pág. 246) refiriéndose a la primera fase del constitucionalismo dirá que «libertad de expresión, la libertad de cátedra y de prensa fueron otros tantos derechos, individuales pero políticos - más del Ciudadano que del Hombre- que abrieron camino a posteriores derechos colectivos y democráticos como los de reunión y asociación».

${ }^{29}$ Piénsese en el condicionamiento insalvable que para el elector suponen las listas cerradas y bloqueadas.

${ }_{30}$ El Tribunal Constitucional español ha dicho en sentencia de 14 de julio del 81 que «la eventual limitación o suspensión de derechos fundamentales tiene una dimensión nacional. Esta limitación o suspensión de derechos fundamentales en una democracia sólo se justifica en aras de la defensa de los propios derechos fundamentales cuando determinadas acciones, por una parte, limitan o impiden de hecho su ejercicio en cuanto derechos subjetivos para la mayoria de los ciudadanos, y por otra, ponen en peligro el ordenamiento objetivo de la comunidad nacional, es decir, el estado democrático".

${ }_{31}$ Op. cit., pág. 306 . Sin perjuicio, como se advierte en el texto, de que el autor hace extensiva esta vez su afirmación a otros grupos de derechos. 
portancia en la vida política de los Estados, dirá que son, justamente, «las que pretenden impedir - y en cierta manera lo van logrando- que el Estado se convierta en coto privado de unas oligarquias gobernantes sometidas tan sólo a un autocontrol endógeno y a la tentación permanente de sustituir el consenso del Estado por un compromiso de distribución entre ellas de unos poderes que han de pertenecer a todos los ciudadanos.

\section{Las libertades públicas como derechos limitados}

Por último, son libertades cuyo reconocimiento, por las especiales características aquí referidas, se ve acompañado de condicionamientos o de remisiones a la ley ${ }^{32}$. En efecto, en el momento de su propio reconocimiento suelen ir acompañados de límites, generalmente derivados de su ejercicio en sociedad; así, los derechos o libertades de residencia, movimiento, expresión, reunión, asociación, enseñanza, cátedra, etc. cuyo ejercicio subjetivo, como derechos, además de ser susceptible de suspensión temporal, exije el reconocimiento de un ámbito de libertad, entendido como espacio y técnica jurídica, sometido a límites variables con tal que se respete su contenido esencial ${ }^{33}$.

\section{EL CATÁLOGO DE LAS LIBERTADES PÜBLICAS}

\section{Homogeneldad del grupo pese a su historicidad}

De las notas que acabamos de apuntar, como puntos de partida y reflexión para la determinación de las libertades públicas, se desprende que su historicidad impone cierta relatividad al catálogo de las mismas o, cuanto menos, al papel histórico político que cada una de ellas ha ido desempeñando. Sin embargo, vale la pena también observar que, pese a tal flexibilidad interna en el grupo de libertades, y a la eventual adición o sus-

32 Del carácter de función social de los derechos se deriva, dice L. SÁNCHEZ AGESTA (op. cit., pág. 495) su regulación por una «ley de organización”.

33 O, como advierte I. DE OTTO (L. MARTIN RETORTILLO, I DE OTTO: Derechos fundamentales y Constitución. Madrid, Civitas, 1988, págs. 135 y ss.) con un contenido bien delimitado por la propia Constitución a partir del cual sólo de manera impropia se puede hablar de límites. De todo ello nos ocupamos en el libro, ya cit., Libertades Públicas. 
tracción de algunas en determinados momentos, es un grupo de derechos que mantiene una cierta homogeneidad ${ }^{34}$ a lo largo de la historia de éstos y que no sufre tan directamente como otros la evolución de la misma.

Me refiero a que, como conjunto, siguen manteniendo su fundamentación, caracteristicas, etc., sin observarse la extraordinaria mutación que otros, algunas libertades individuales, han sufrido en las sociedades contemporáneas. En cambio sí es patente esa flexibilidad o fluibilidad en el interior del grupo de libertades públicas, lo que es consecuencia tanto de la mutabilidad de cada una de ellas, generalmente con carácter expansivo ${ }^{35}$ como por la movilidad o sucesión del protagonismo o carácter axial que una o alguna haya podido tener en diversas etapas históricopolíticas.

En el primer aspecto, cabe pensar como ejemplo en la progresiva ampliación del ámbito de la libertad religiosa hasta comprender, también, la de cultos y proselitismo o en la de la libertad de asociación (autorizada al principio sólo con fines benéficos) hasta lograr el reconocimiento de su manifestación más claramente política (los partidos políticos), etc. ${ }^{36}$. En el segundo aspecto, es obvio que la libertad de asociación politica, hoy quizá la más relevante, ocupa este lugar en perjuicio de las que en otros momentos lo ocupaban (la libertad de imprenta en el primer constitucionalismo escrito o la libertad de reunión cuando ésta constituía, junto con aquélla, el principal vehículo de la información y manifestación políticas).

De ahí que en su origen, evolución y diversa configuración, su posición en el sistema de derechos esté intimamente condicionada por el tipo de régimen de que se trate; pero, en todo caso, constituyen un bloque para el que, sea el poder, sea el derecho, adoptan posiciones globales o generales para todo el grupo. Los regímenes democráticos ni que decir tiene que reconocen las libertades públicas y que las protegen y garantizan. Nuestra Constitución vigente es un buen ejemplo de régimen en el que alcanzan idéntica protección a los derechos fundamentales (entendidos

34 A ellas, y desde la perspectiva de su regulación en el derecho decimonónico español, se refiere J. M. ROMERo MORENo (op. cit., pág. 52) como caquel conjunto de libertades que de alguna manera no consiste en un "espacio" de autonomia, sino que exigen un facultativo ejercicio del sujeto - voluntario o activo-y para el que hay que asegurar condiciones de ejercitabilidad: así, la expresión e imprenta, enseñanza, petición, manifestación, reunión o asociación.

${ }_{35}$ Piénsese, por ejemplo, en las múltiples posibilidades y facultades que se han ido derivándo de la originaria libertad de imprenta y prensa.

${ }^{36}$ En este punto, y al observar la evolución de cada una de las libertades, es decisivo tener en cuenta la consideración que sobre las mismas tiene en cada momento el poder $y$, más en concreto los intereses políticos; así, la libertad de cátedra desempeña un papel crucial en los primeros momentos de la Restauración con el desencadenamiento, por obra de medidas adoptadas desde el poder público (la circular Orovio), de la llamada cuestión universitaria. También, en la evolución de las diversas libertades deben tenerse en cuenta otros factores como, en el caso de la libertad de expresión, los efectos que sobre la misma ha ido desplegando el extraordinario avance de la técnica. 
como fuertes o merecedores de la mayor protección que el artículo 53.2 CE

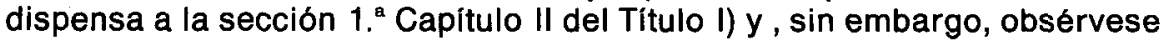
como en nuestro caso, igual que en los homólogos del área occidental, cabe la suspensión de los derechos tradicionalmente considerados libertades públicas.

Ello nos permite confirmar las notas más arriba expuestas: obsérvese que no se suspenden los derechos más personales, los personalisimos o básicos como es lógico; pero tampoco los políticos que, por el contrario, se fortalecen indirectamente por las garantías que suelen rodear los supuestos de suspensión imponiendo el normal funcionamiento de las instituciones ${ }^{37}$. No sería aventurado suponer, a la vista de estas primeras consideraciones, que ni unos ni otros amenazan el orden democrático. En cambio, éste suele resguardarse de los riesgos graves acudiendo a la suspensión de las Ilamadas Libertades Públicas.

\section{Enumeración de las libertades públicas}

Pues bien, generalmente, se han venido considerando libertades públicas, las siguientes: libertad religiosa (hoy también ideólogica), libertad de enseñanza, libertad de cátedra, libertad de reunión, libertad de asociación (dentro de la cual destacan - por obra de ese carácter expansivo antes referido- la de asociación política y la libertad sindical), libertad de residencia (ésta sólo en su aspecto más politizado), libertad de movimientos - circulación (de la que cabe hacer la misma advertencia que en la anterior), libertad de expresión (que en realidad, en un sentido amplio, comprende todas las demás, lo que quizá se pone más de manifiesto con la denominación que recibe en Italia: libertad de manifestación de pensamiento) y, por último, el derecho de petición (en uno solo de sus aspectos: el de poder manifestarse libremente - sin miedo a represalias-, no como en las demás libertades públicas ante la sociedad, sino ante el poder y sus autoridades).

A modo de conclusión, creo que cabe aún una última advertencia que, pese a su obviedad, no puede pasar desapercibida. Ni que decir tiene que las libertades públicas no son sino manifestaciones aisladas o parcelas de la libertad de la persona. Las libertades públicas no tienen sentido, ni caben siquiera, sin la libertad individual, la moral y la física, ni se nos oculta tampoco la estrecha conexión que guardan, aunque no deban confundirse, con las libertades individuales o derechos «del hombre aislado». De otra parte, es conocida la dificultad de establecer en cualquier rama o aspecto 
del derecho límites estrictos y quizá donde ésta se presente con mayor claridad es en la delimitación de las diversas manifestaciones de la dignidad humana y de la libertad.

Efectivamente, en muchas ocasiones el término libertad pública no hace sino traducir la cara social de un derecho o libertad individual; tal vez el ejemplo más claro sería el de la libertad de conciencia que, en cuanto necesite manifestarse exteriormente mediante el culto, la enseñanza, o el proselitismo, estará constituyendo libertades públicas. Pero, en todo caso, creo que, pese a estas conexiones, siguen en pie las características más arriba apuntadas y el régimen jurídico, que de ellas se desprende pues en el caso del ejemplo que se acaba de poner, las manifestaciones de culto, la enseñanza o el proselitismo como expresión de la libertad de conciencia, en tanto que libertades públicas quedan sometidas a un régimen jurídico y a unas limitaciones que, sin duda, no cabe aplicar a la simple e individual libertad de conciencia ${ }^{38}$. 